Portland State University

PDXScholar

Electrical and Computer Engineering Faculty

Publications and Presentations

$5-1-2007$

\title{
Electrical Skin Impedance at Acupuncture Points
}

\author{
Sean Pearson \\ Portland State University \\ Agatha P. Colbert \\ National College of Natural Medicine \\ James McNames \\ Portland State University \\ Meggan Baumgartner \\ Oregon College of Oriental Medicine \\ Richard Hammerschlag \\ Oregon College of Oriental Medicine
}

Follow this and additional works at: https://pdxscholar.library.pdx.edu/ece_fac

Part of the Electrical and Computer Engineering Commons

Let us know how access to this document benefits you.

\section{Citation Details}

Pearson, S., Colbert, A. P., McNames, J., Baumgartner, M., \& Hammerschlag, R. (2007). Electrical Skin Impedance at Acupuncture Points.

This Article is brought to you for free and open access. It has been accepted for inclusion in Electrical and Computer Engineering Faculty Publications and Presentations by an authorized administrator of PDXScholar. Please contact us if we can make this document more accessible: pdxscholar@pdx.edu. 


\title{
Electrical Skin Impedance at Acupuncture Points
}

\author{
SEAN PEARSON, B.S., ${ }^{1}$ AGATHA P. COLBERT, M.D., ${ }^{2}$ JAMES McNAMES, Ph.D., ${ }^{1}$ \\ MEGGAN BAUMGARTNER, M.Ac.O.M., ${ }^{3}$ and RICHARD HAMMERSCHLAG, Ph.D. ${ }^{3}$
}

\begin{abstract}
Objective: To test whether electrical skin impedance at each of three acupuncture points (APs) is significantly lower than at nearby sites on the meridian (MP) and off the meridian (NP).

Design: Two instruments-Prognos (MedPrevent GmbH, Waldershof, Germany), a constant-current (DC) device, and PT Probe (designed for this study), a 100-Hz sinusoidal-current (AC) device-were used to record electrical impedance at three APs (right Gallbladder 14, right Pericardium 8, and left Triple Energizer 1), and two control sites for each AP. Each AP, MP, and NP was measured four times in random order with each device.

Setting: The study was conducted over a period of 4 days at the Oregon College of Oriental Medicine (OCOM).

Subjects: Twenty (20) healthy adults (14 women and 6 men), all recruited from the OCOM student body and faculty, participated in the study.

Results: The Prognos measurements had an intraclass correlation (ICC) $=0.84$ and coefficient of variation $(\mathrm{CV})=0.43$. The PT Probe had ICC $=0.81$ and $\mathrm{CV}=0.31$. Impedance values at APs were not significantly less than at MPs or NPs. Impedance values at MPs were also not significantly less than NPs, although their individual $p$ values were $<0.05$ in 4 of 6 cases. There was a significant trend of increasing impedance with repeated measurements with both the Prognos $(p=0.003)$ and the PT Probe $(p=0.003)$.

Conclusions: Within the reliability limits of our study methods, none of the three APs tested has lower skin impedance than at either of the nearby control points. These results are not consistent with previous studies that detected lower skin impedance at APs than nearby sites. Further study is necessary to determine whether MPs have lower skin impedance than nearby NPs. Our study suggests caution is warranted when developing, using, and interpreting results from electrodermal screening devices. Further studies are needed to clarify the clinically important and controversial hypothesis that APs are sites of lower impedance.
\end{abstract}

\section{INTRODUCTION}

$\mathbf{E}$ lectrodermal screening, as practiced by acupuncturists and homeopathic clinicians, measures either skin impedance or conductance at acupuncture points (APs) as diagnostic aids for planning treatment strategies. Skin impedance is the skin's opposition to the flow of current. The impedance of skin is a function of both resistive (frequency independent) and capacitive (frequency dependent) elements. The practice of measuring skin impedance is based on the widely held assumption that APs are loci of decreased impedance compared to skin sites where there are no known APs. Research performed in an unblinded manner several decades ago by Niboyet et al., ${ }^{1}$ Nakatani, ${ }^{2}$ and Voll $^{3}$ first

\footnotetext{
${ }^{1}$ Biomedical Signal Processing Laboratory, Portland State University, Portland, OR.

${ }^{2}$ Helfgott Research Institute, National College of Natural Medicine, Portland, OR.

${ }^{3}$ Research Department, Oregon College of Oriental Medicine, Portland, OR.
} 


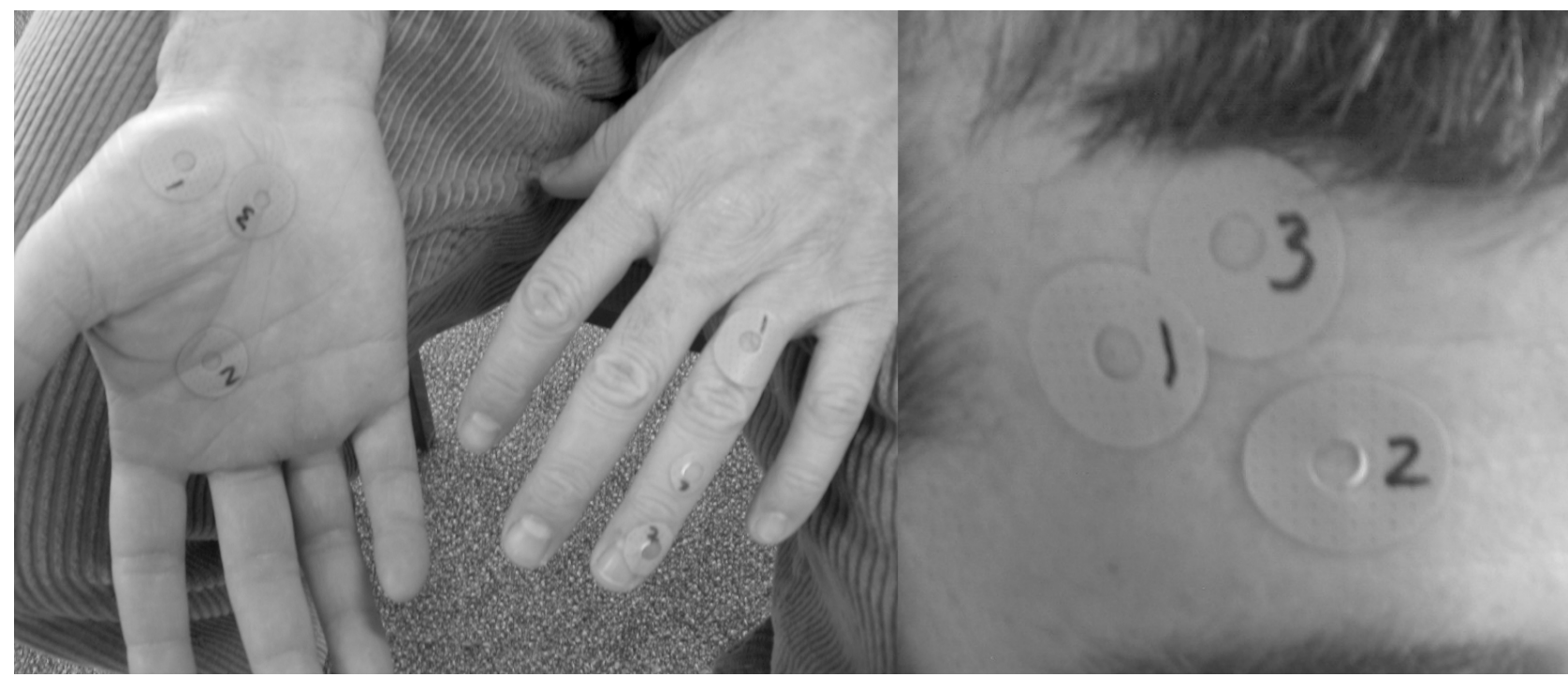

FIG. 1. Typical site locations near Pericardium (PC) 8, Triple Energizer (TE) 1, and Gallbladder (GB) 14.

demonstrated evidence of these phenomena. More recent studies, performed under stricter conditions, ${ }^{4-12}$ confirmed these findings.

Three groups of researchers, however, using blinded evaluators and rigorous statistical analyses, concluded that, based on skin impedance measurements, APs could not be distinguished from non-AP sites. ${ }^{13-15}$ The latter investigators point out the many possible sources of error associated with skin impedance measurements. These confounders are related primarily to the skin/electrode interface and include probe size and shape, pressure exerted by the probe, duration of probe application, inclination of the probe tip on the skin, and variations in skin condition (dry/moist, thickness and integrity of the stratum corneum). Skin impedance measurements also vary with the frequency of applied current ${ }^{16,17}$ and with several instrumentation parameters, including whether a multichannel system, ${ }^{7,9,18}$ a concentric probe, ${ }^{8}$ a four-electrode system, ${ }^{9,16,19}$ or a two-electrode system is used. Recommended AC frequency choices have included $100 \mathrm{~Hz}^{17}$ and $200 \mathrm{kHz} .{ }^{17,20}$ Impedance readings may also be influenced by fluctuations in the underlying psychophysiologic condition of the subject and potential investigator bias when an acupuncturist performs the evaluation. ${ }^{15}$

Skin impedance varies with the frequency at which it is measured. Rosendal proposed an electrical model for skin impedance that is commonly used. ${ }^{21}$ Steady-state alternating current (AC) and direct current (DC) instruments are sensitive to different components of this model. For example, capacitive components only allow current to flow when the current fluctuates, as occurs with AC instruments, and is not detected by constant current (DC) instruments. Highfrequency measurements $(>10,000 \mathrm{~Hz})$ can be sensitive to stray capacitance.
As part of a program of research exploring the properties of the Ting (Jing well) APs, we have conducted a study with Prognos (MedPrevent GmbH, Waldershof, Germany), a commercially available DC ohm meter designed for measuring skin impedance. ${ }^{22}$ In order to compare the Prognos impedance readings with readings acquired using $\mathrm{AC}$, we also designed and implemented a customized system called the PT Probe, which was designed for this study.

The purpose of this study was to assess, under blinded conditions (with constant probe pressure), whether APs are sites of lower impedance compared to non-AP sites when measured with either DC or AC devices. We chose to evaluate three classical APs: Triple Energizer 1 (TE 1), which is located at the lateral corner of the nail bed on the fourth digit of the hand; Pericardium 8 (PC 8), which is located in the palm of the hand; and Gallbladder 14 (GB 14), which located on the forehead above the eye. (Acupuncture points are signified by the Stan-

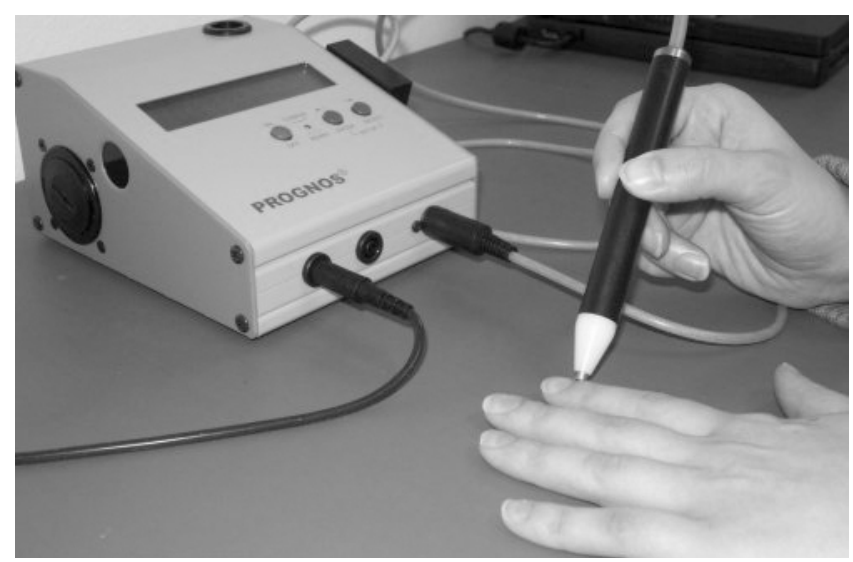

FIG. 2. Prognos (MedPrevent GmbH, Waldershof, Germany). 


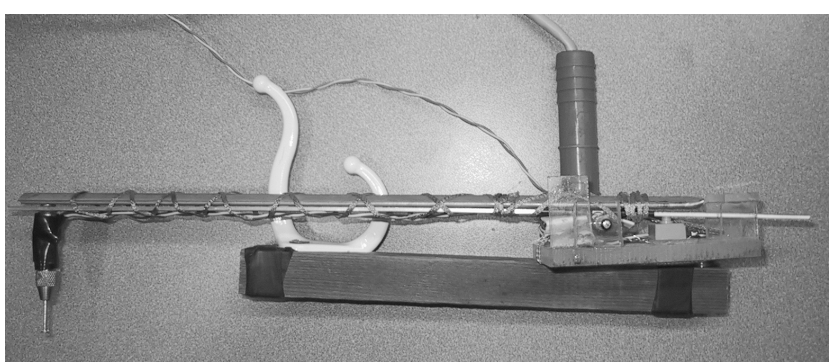

FIG. 3. PT Probe (designed for study).

dard Acupuncture Nomenclature of the World Health Organization (1993)). These APs were selected because of their distinct anatomical and topographical features and their clinical importance. We hypothesized that impedance at each of three APs would be significantly lower than two nearby (within 5 $\mathrm{cm}$ ) control sites, which consisted of a site on the related meridian (MP) and a site off the meridian (NP). We also tested a second hypothesis that the impedance on the MP would be less than on the NP. Finally, we tested a hypothesis that repeated measurements would not affect the mean skin impedance.

\section{METHODS}

\section{Participants and settings}

Participants were recruited from the Oregon College of Oriental Medicine faculty and student body. The study was approved by the OCOM Institutional Review Board (IRB). Twenty (20) adult participants (14 females and 6 males) ages 23-65 were evaluated at OCOM after signing approved consent forms. Inclusion criteria included healthy participants with the ability to sit quietly for 30 minutes while the measurements were taken.

\section{Selection of data points}

APs are located relative to anatomical landmarks based on textbook descriptions and charts, palpation, and visual inspection. In clinical practice, APs may be palpated as areas of induration or indentation, increased warmth, and/or changes in color or sensation. Another important element of acupoint selection in clinical practice and in this study is the acupuncturist's perceived sense of the level of "energy flow" or $q i$ at the acupoint. TE 1 was selected because of its location on the finger tip and because it has been used in other research studies with the Prognos. ${ }^{22,23}$ GB 14 was selected because of its accessibility, flat anatomical feature, and common clinical usage. PC 8 was selected because of its accessibility and what our expert acupuncturists described as an "easily felt sense of $q i$. ." MPs were identified as points on the same meridian that were clearly not classical Chinese APs. NPs were identified as other nearby points that were not on the meridian and had substantially less "sensation of $q i$ " than the corresponding APs.

\section{Point location consensus}

Four licensed acupuncturists practicing for 5 or more years were trained in advance to come to consensus about the location of the AP, MP, and NP sites. At each session, three of the acupuncturists located the sites using visual inspection, digital palpation, and "sensation of qi." Although there was no time limit given to the acupuncturists to come to consensus on all nine study sites on each person, the process took 10-15 minutes for each participant. Typical point locations for the sites near TE 1, PC 8, and GB 14 are shown in Figure 1.

\section{Equipment}

Prognos. The Prognos is used clinically to measure skin impedance at Ting (Jing well) acupuncture points located at the corners of the finger and toenail beds. It was found to be reliable for repeat measurements at these acupuncture points. ${ }^{22,23}$ The Prognos uses a $4.57-\mathrm{mm}$-diameter probe tip. It averages 400 measurements taken during approximately 200 milliseconds. When triggered at a pressure of approximately $163 \pm 3 \mathrm{kPa}$, Prognos applies a DC current of 1.1 $\mu \mathrm{A}$. The Prognos is shown in Figure 2.

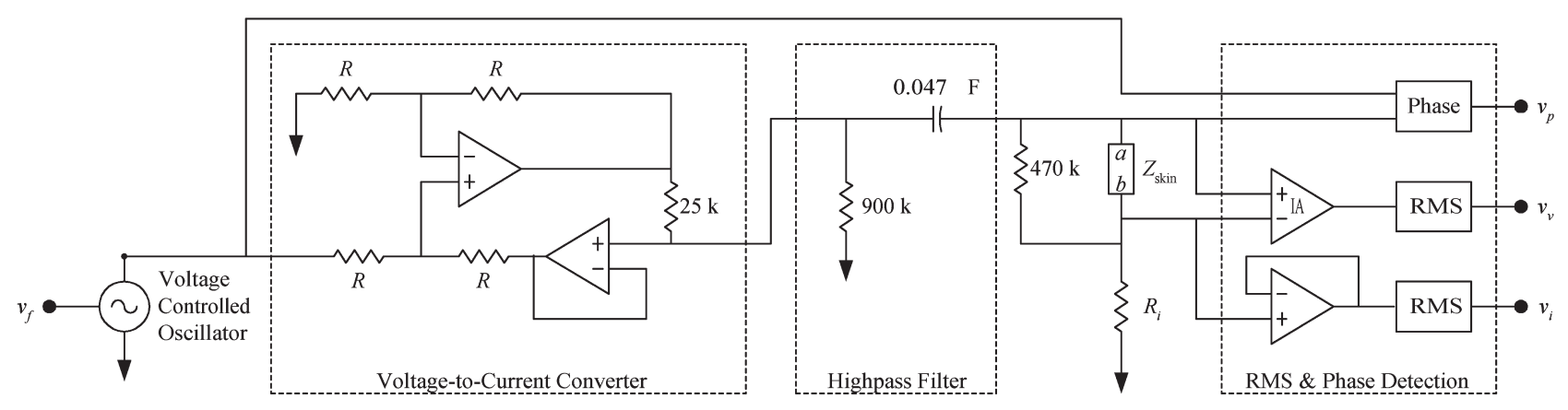

FIG. 4. Impedance circuit. 


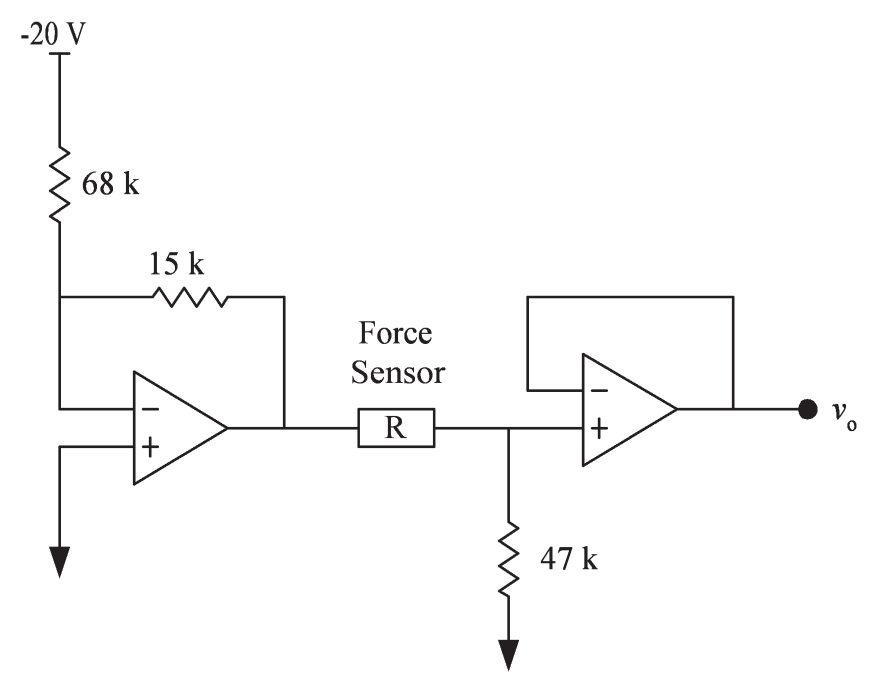

FIG. 5. Force sensor circuit.

PT Probe. The second device, which was designed and built for this study, is called the PT Probe. It consists of a probe, signal-conditioning circuitry, and a laptop-based data acquisition system. The probe was designed to trigger at approximately the same pressure as the Prognos. We used a lever design to achieve a suitable input for the pressure sensor. A metal probe tip with a diameter of $3.56 \mathrm{~mm}$ was used. A handle allowed the measurements to be easily taken. The PT Probe is shown in Figure 3.

We developed circuitry to measure skin impedance and convert force sensor resistance into a voltage. ${ }^{24} \mathrm{~A}$ circuit diagram is shown in Figure 4. A 470-k $\Omega$ resistor in parallel with the skin was added and the current source was reduced to $14.2 \mu \mathrm{A}$ to increase the measurable impedance range. Unlike the Prognos, the PT Probe applied a sinusoidal current with a frequency of $100 \mathrm{~Hz}$. The voltage across the resistor-skin parallel combination was recorded by a data acquisition card onto a laptop computer. The load impedance $\mathrm{Z}_{\mathrm{S}}$ was calculated as $\mathrm{Z}_{\mathrm{S}}=\mathrm{R}_{\mathrm{P}} /\left(\left(\mathrm{I}_{\mathrm{RMS}} \times \mathrm{R}_{\mathrm{P}} / \mathrm{V}_{\mathrm{RMS}}\right)-1\right)$, where $R_{P}$ is the value of the parallel resistor and $I_{R M S}$ and $\mathrm{V}_{\mathrm{RMS}}$ are the root-mean-squared current and voltage, respectively. The maximum current through the skin was limited to $14.2 \mu \mathrm{A}$, and the maximum voltage was limited to $6.8 \mathrm{~V}$.

A force sensor (CUI Inc. IESP-12) was used to control the pressure at which the measurements were taken. A simple circuit shown in Figure 5 was used to convert the sensor resistance into a voltage. The circuit produced a voltage of 2.7-3.5 V when a force of $0.75-1.22 \mathrm{~N}$ was applied to the probe tip. This force applied over the $9.95 \mathrm{~mm}^{2}$ area of the probe tip gives a pressure of $75-122 \mathrm{kPa}$.

The voltages were acquired with a National Instruments (Austin, TX) 6062-E DAC and stored on a laptop computer. The signals were sampled at $5 \mathrm{kHz}$ and decimated to 500 $\mathrm{Hz}$. The voltage was squared and lowpass filtered. The square root was then taken to obtain the root mean squared voltage. This voltage was averaged over the 2 -second interval for which the pressure sensor voltage was in the 2.7-5.4 $\mathrm{V}$ range.

\section{Protocol}

Electrical impedance at three APs (right GB 14, right PC 8, and left TE 1) and the corresponding MPs and NPs were measured on each of the 20 participants with both devices.

Once the three acupuncturists came to consensus on the point, circular adhesives with a 5-mm-diameter central perforation were placed over each of the nine agreed-upon sites on each participant and then were coded for data collection purposes. The skin was prepared by exfoliation with tape (five times per site) and then cleansed with ethyl alcohol. Digital photographs of all of the marked sites were taken for each participant (Fig. 1).

Participants were asked to sit quietly while the measurements were obtained with both devices. The probe tips were cleansed with ethyl alcohol at the beginning of each session. The technician who acquired the measurements was not an acupuncturist. Each AP, MP, and NP was measured four times by each device in random order. Half of the partici-

Table 1. Prognos ${ }^{\mathrm{a}}$ and PT Probe ${ }^{\mathrm{b}}$ Reliability

\begin{tabular}{|c|c|c|c|c|}
\hline & $\begin{array}{l}\text { Mean of } \\
\text { medians }\end{array}$ & $\begin{array}{l}\text { Standard deviation } \\
\text { within participants }\end{array}$ & $\begin{array}{l}\text { Standard deviation } \\
\text { between participants }\end{array}$ & $I C C$ \\
\hline \multicolumn{5}{|l|}{ Prognos } \\
\hline GB 14 & 2469 & 2039 & 5428 & $0.88(0.82-0.92)$ \\
\hline PC 8 & 5077 & 3093 & 9028 & $0.89(0.85-0.93)$ \\
\hline TE 1 & 10,877 & 7482 & 14,000 & $0.78(0.69-0.85)$ \\
\hline \multicolumn{5}{|l|}{ PT Probe } \\
\hline GB 14 & 750 & 1108 & 1165 & $0.53(0.40-0.65)$ \\
\hline PC 8 & 5320 & 6412 & 11,214 & $0.75(0.66-0.83)$ \\
\hline TE 1 & 8149 & 5764 & 12,972 & $0.84(0.77-0.89)$ \\
\hline
\end{tabular}

${ }^{\mathrm{a} M e d P r e v e n t ~ G m b H, ~ W a l d e r s h o f, ~ G e r m a n y . ~}$

besigned for this study.

ICC, intraclass correlation; GB, Gallbladder; PC, Pericardium; TE, Triple Energizer. 
Table 2. Prognos ${ }^{\mathrm{a}}$ Intra- and Interperson Variability

\begin{tabular}{|c|c|c|c|c|c|c|}
\hline & $\begin{array}{l}\text { Mean } \\
(\mathrm{N})\end{array}$ & Median & Range (Min-Max) & $\begin{array}{l}\text { Standard deviation } \\
\text { within participants }\end{array}$ & $\begin{array}{l}\text { Standard deviation } \\
\text { between participants }\end{array}$ & $I C C$ \\
\hline \multicolumn{7}{|l|}{ GB 14} \\
\hline $\mathrm{AP}$ & 4.0 & 694 & 1864 (145-2009) & 2219 & 7870 & $0.93(0.86-0.97)$ \\
\hline MP & 4.0 & 333 & 433 (182-615) & 1374 & 1356 & $0.49(0.27-0.72)$ \\
\hline NP & 4.0 & 994 & $1616(448-2064)$ & 2379 & 4911 & $0.81(0.67-0.91)$ \\
\hline \multicolumn{7}{|l|}{ PC 8} \\
\hline AP & 3.6 & 3256 & $1764(2776-4540)$ & 2928 & 8384 & $0.89(0.80-0.95)$ \\
\hline MP & 3.7 & 2928 & 2009 (2354-4363) & 2784 & 8254 & $0.90(0.81-0.95)$ \\
\hline NP & 3.8 & 2909 & $1778(2337-4115)$ & 3501 & 10,647 & $0.90(0.82-0.96)$ \\
\hline \multicolumn{7}{|l|}{ TE 1} \\
\hline $\mathrm{AP}$ & 3.8 & 6882 & $8588(3663-12,251)$ & 7351 & 9458 & $0.62(0.41-0.81)$ \\
\hline MP & 3.8 & 3553 & $1694(2111-3805)$ & 4931 & 12,376 & $0.86(0.75-0.94)$ \\
\hline $\mathrm{NP}$ & 3.8 & 12493 & $14535(4820-19,355)$ & 9496 & 18,064 & $0.78(0.63-0.90)$ \\
\hline
\end{tabular}

aMedPrevent GmbH, Waldershof, Germany.

ICC, intraclass correlation; GB, Gallbladder; AP, acupuncture point; MP, on the meridian; NP, off the meridian; PC, Pericardium; TE, Triple Energizer.

pants had Prognos measurements taken first and half had the PT Probe measurements taken first. Prognos measurements were recorded into a spreadsheet by a second technician. The PT Probe measurements were automatically recorded into a custom data acquisition program. Neither technician knew the mapping between codes and sites.

\section{Device reliability}

Both the Prognos and the PT Probe were tested against a set of nine known resistors ranging from 0 to $5 \mathrm{M} \Omega$ before and after the recordings were taken for each day of the study. Measurements with poor electrical contact were excluded.

To determine the reliability of the devices, four repeated measurements were obtained from each of the nine sites (an
AP, MP, and NP at each of the three APs) with each device from each participant for a total of 36 measurements per participant. The reliability of each device was quantified with two normalized indices: the intraclass correlation coefficient (ICC) and the coefficient of variation $(\mathrm{CV}){ }^{25,26}$ An ICC close to 1 indicates that the repeated measurements produce consistent values as compared to the differences between sites and indicates that the device can reliably distinguish between sites. A small CV indicates that repeated measurements at the same site are consistent.

\section{Statistical analysis}

In some cases, the Prognos was unable to provide a measurement, so fewer than four measurements were available

TAble 3. PT Probe a Intra- ANd Interperson Variability

\begin{tabular}{|c|c|c|c|c|c|c|}
\hline & $\begin{array}{l}\text { Mean } \\
\text { (N) }\end{array}$ & Median & Range (Min-Max) & $\begin{array}{l}\text { Standard deviation } \\
\text { within participants }\end{array}$ & $\begin{array}{l}\text { Standard deviation } \\
\text { between participants }\end{array}$ & $I C C$ \\
\hline \multicolumn{7}{|l|}{ GB 14} \\
\hline $\mathrm{AP}$ & 4.0 & 405 & $372(163-534)$ & 928 & 963 & $0.52(0.30-0.73)$ \\
\hline MP & 4.0 & 244 & $305(153-459)$ & 1328 & 984 & $0.35(0.14-0.61)$ \\
\hline NP & 4.0 & 534 & 717 (187-903) & 1028 & 1527 & $0.69(0.50-0.84)$ \\
\hline \multicolumn{7}{|l|}{ PC 8} \\
\hline AP & 4.0 & 2142 & 762 (1867-2629) & 5143 & 15914 & $0.91(0.83-0.96)$ \\
\hline MP & 4.0 & 2318 & $551(2094-2644)$ & 7774 & 10368 & $0.64(0.44-0.81)$ \\
\hline NP & 4.0 & 2238 & $864(2004-2868)$ & 6037 & 5108 & $0.42(0.19-0.66)$ \\
\hline \multicolumn{7}{|l|}{ TE 1} \\
\hline $\mathrm{AP}$ & 4.0 & 3496 & $2230(2445-4676)$ & 6040 & 13672 & $0.84(0.71-0.92)$ \\
\hline MP & 4.0 & 2465 & $1048(2314-3362)$ & 6489 & 16625 & $0.87(0.76-0.94)$ \\
\hline $\mathrm{NP}$ & 4.0 & 3979 & $2280(3016-5297)$ & 4590 & 7526 & $0.73(0.55-0.87)$ \\
\hline
\end{tabular}

aDesigned for this study.

ICC, intraclass correlation; GB, Gallbladder; AP, acupuncture point; MP, on the meridian; NP, off the meridian; PC, Pericardium; TE, Triple Energizer. 
TABle 4. Prognos ${ }^{\mathrm{a}}$ Intersite Variability

\begin{tabular}{|c|c|c|c|c|}
\hline & $\begin{array}{l}\text { Mean of } \\
\text { medians }\end{array}$ & $\begin{array}{c}\text { Median of } \\
\text { medians }\end{array}$ & $\begin{array}{l}\text { Standard } \\
\text { deviation }\end{array}$ & Range (min, $\max$ ) \\
\hline \multicolumn{5}{|l|}{ GB 14} \\
\hline NP-AP & 100 & 149 & 7944 & $45,461(-24,635,20,826)$ \\
\hline NP-MP & 2364 & 604 & 5543 & $27,173(-5911,21,262)$ \\
\hline NP-NP & -2264 & -198 & 7934 & $38,065(-33,514,4551)$ \\
\hline \multicolumn{5}{|r|}{ ( ) } \\
\hline NP-AP & -666 & -5 & 3404 & $15,345(-9195,6150)$ \\
\hline NP-MP & 246 & 340 & 4015 & $19,311(-12,958,6353)$ \\
\hline NP-NP & -572 & -258 & 4568 & $24,862(-12,337,12,525)$ \\
\hline \multicolumn{5}{|l|}{ TE 1} \\
\hline NP-AP & 5506 & 1802 & 16,111 & $77,033(-23,176,53,857)$ \\
\hline NP-MP & 6030 & 1920 & 15,831 & $74,114(-28,892,45,222)$ \\
\hline NP-NP & -2829 & -3125 & 12,983 & $50,789(-20,082,30,707)$ \\
\hline
\end{tabular}

aMedPrevent GmbH, Waldershof, Germany.

GB, Gallbladder; NP, off the meridian; AP, acupuncture point; MP, on the meridian; PC, Pericardium; TE, Triple Energizer.

for analysis. The median of the available measurements was used for the hypothesis tests.

Preliminary measurements with both devices produced significant outliers with a skewed distribution, so we used the nonparametric sign test to compare impedance at two sites. For each of the two devices and each of the three APs, we tested whether the impedance at the AP was lower than the corresponding MP, whether the impedance at the AP was lower than the corresponding NP, and whether the impedance at the MP was lower than the NP for a total of 18 comparisons $(2$ devices $\times 3$ AP sites $\times 3$ comparisons at each site). We used a modified test level of significance on the 18 impedance comparisons to obtain a family level of significance of 0.05 . The level of significance of the individual test was 0.00283 .

We also tested for a trend of increasing or decreasing impedance with repeated measurements from each device for a total of two additional hypothesis tests. For the trend tests, the Cox and Stuart test for trend was used to compare consecutive measurements. ${ }^{27}$ At each unique point, the first measurement was compared with the third and the second with the fourth. If there were only three measurements, then only the first and third were compared. If there were two measurements, they were compared with each other. Our test statistic was the total number of times the later measurements were higher than earlier measurements among all of the points. The trend tests were conducted with a separate family level of significance of 0.05 . The level of significance of the individual test was 0.02532 .

\section{RESULTS}

The Prognos resistance measurements had an ICC $=1.00$ and standard deviation of $20.5 \mathrm{k} \Omega$ or $1.4 \%$ of the overall

TABle 5. PT Probe ${ }^{\mathrm{a}}$ InTERsite VAriability

\begin{tabular}{|c|c|c|c|c|}
\hline & $\begin{array}{l}\text { Mean of } \\
\text { medians }\end{array}$ & $\begin{array}{c}\text { Median of } \\
\text { medians }\end{array}$ & $\begin{array}{l}\text { Standard } \\
\text { deviation }\end{array}$ & Range (min, $\max )$ \\
\hline \multicolumn{5}{|l|}{ GB 14} \\
\hline NP-AP & 204 & 74 & 2125 & $12,447(-4761,7686)$ \\
\hline NP-MP & 290 & 65 & 1250 & $7050(-2590,4460)$ \\
\hline NP-NP & 86 & 18 & 1608 & $8286(-3444,4842)$ \\
\hline \multicolumn{5}{|l|}{ PC 8} \\
\hline NP-AP & -3317 & -344 & 8709 & $40,453(-38,612,1841)$ \\
\hline NP-MP & -2294 & -340 & 12,271 & $56,396(-54,938,1458)$ \\
\hline NP-NP & -1023 & -347 & 4227 & $21,324(-16,326,4998)$ \\
\hline \multicolumn{5}{|l|}{ TE 1} \\
\hline NP-AP & -1098 & 828 & 17,090 & $81,498(-57,716,23,782)$ \\
\hline NP-MP & -2397 & 648 & 12,967 & $71,987(-47,586,24,401)$ \\
\hline NP-NP & 1299 & -528 & 19,772 & $106,356(-41,994,64,362)$ \\
\hline
\end{tabular}

aDesigned for this study.

GB, Gallbladder; NP, off the meridian; AP, acupuncture point; MP, on the meridian; PC, Pericardium; TE, Triple Energizer. 
mean. The PT Probe had an ICC $=1.00$ and standard deviation of $33.2 \mathrm{k} \Omega$ or $2.2 \%$ of the overall mean.

The Prognos skin measurements had an intraclass correlation $\mathrm{ICC}=0.84$ and an average $\mathrm{CV}=0.43$. The PT Probe skin measurements had an ICC $=0.81$ and an average $\mathrm{CV}=$ 0.31 . Table 1 lists reliability statistics for the two devices. Tables 2 and 3 show inter- and intraperson variability. Tables 4 and 5 show intersite variability. For these tables, the median of the four measurements at one site for each person was subtracted from that of a neighboring site. All impedance values are listed in units of $\mathrm{k} \Omega$.

Tables 6-8 list the hypothesis test $p$ values. In some participants, we were unable to obtain readings from the Prognos because these readings were out of the range of the instrument. Because of this, the average number of measurements is reported in Tables 2 and 3, and numbers of valid pairs for comparison are reported for the Prognos in Tables 6-8. Tables 9 and 10 list the median impedance at each point measured for each device. A value of NA indicates that we were unable to obtain any measurements for that point.

Skin impedance at APs was not significantly less than at MPs, skin impedance at APs was not significantly less than at NPs, and skin impedance at MPs was not significantly less than at NPs at any of the three APs measured with either device.

There was a significant trend of increasing impedance in the repeated measurements from both Prognos $(p=0.003$, $\mathrm{N}=344)$ and the PT Probe $(p=0.003, \mathrm{~N}=360)$. On average, the impedance increased by $0.62 \%$ or $778 \Omega$ for Prognos, and $4.62 \%$ or $442 \Omega$ for the PT Probe.

\section{DISCUSSION}

Comparisons of skin impedance measurements recorded at different APs and non-AP control sites, using different measuring instruments and techniques is complex. When we measured three classical APs using a two-electrode DC device and a two-electrode AC device, and compared the impedance measurements to those taken at each of two nearby control sites (MPs and NPs), the skin impedance

Table 6. GB 14 Hypothesis Test Results ( $P$ Values)

\begin{tabular}{lccc}
\hline Test & $N\left(\right.$ Prognos $\left.^{\mathrm{a}}\right)$ & Prognos $^{\mathrm{a}}$ & PT Probe $^{\mathrm{b}}$ \\
\hline $\mathrm{AP}<\mathrm{MP}$ & 20 & 0.4119 & 0.1316 \\
$\mathrm{AP}<\mathrm{NP}$ & 20 & 0.1316 & 0.0207 \\
$\mathrm{MP}<\mathrm{NP}$ & 20 & 0.0059 & 0.0059 \\
\hline
\end{tabular}

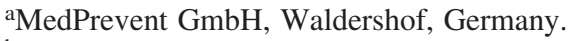

${ }^{b}$ Designed for this study.

$\mathrm{AP}$, acupuncture point; MP, on the meridian; NP, off the meridian.
Table 7. PC 8 Hypothesis Test Results ( $P$ Values)

\begin{tabular}{lccc}
\hline Test & $N\left(\right.$ Prognos $\left.^{\mathrm{a}}\right)$ & Prognos $^{\mathrm{a}}$ & PT $^{\text {Probe }}$ \\
\hline AP $<$ MP & 18 & 0.9519 & 0.9423 \\
AP $<$ NP & 18 & 0.4073 & 0.7483 \\
MP $<$ NP & 19 & 0.0318 & 0.5881 \\
\hline
\end{tabular}

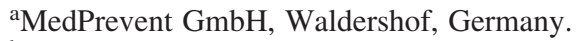

${ }^{b}$ Designed for this study.

$\mathrm{AP}$, acupuncture point; MP, on the meridian; NP, off the meridian.

at APs was not statistically different than at the control sites. However, several of the hypothesis tests had $p$ values $<0.05$. In particular, the trend tests and the tests for MP having lower impedance than NP had low $p$ values $(<0.05)$ in four of six cases. The test results taken collectively are not significant at the 5\% family level of significance, but suggest that lowered skin impedance at MPs warrants further study.

A number of factors may potentially explain the lack of differences in impedance observed between APs, MPs, and NPs. It is possible that indeed, no differences exist or that differences if they do exist appear only during ill health. There may also be some methodological explanations for the lack of differences we found. Our negative findings are in accord with three groups of investigators who demonstrated that the many well-known confounders in impedance measurements preclude a differentiation of APs from surrounding areas. ${ }^{13-15}$ Our results, however, are inconsistent with those of several groups who found significantly lower skin impedance at APs than at non-AP sites using different methods and a variety of instruments. ${ }^{4,6-11,16,18,20,28-30}$

\section{Proximity of AP to non-AP site and probe tip size}

Researchers who used 36- or 256-channel probes (individual probe tip size 1-2-mm diameter) positioned over the site of a classical AP detected loci of significantly lower impedance in relation to the immediate surrounding area (within $2-4 \mathrm{~mm}^{2}$ ) of the center of the site of lowest impedance. ${ }^{6,7,9,28}$ The probes used in our study were substantially larger $(4.5 \mathrm{~mm}$ and $3.5 \mathrm{~mm}$ in diameter) and skin sites with which comparisons were made were up to $5 \mathrm{~cm}$ away. Jakoubek and Rohlicek found that a central point of low impedance coinciding with the site of classical APs was 350 $\mu \mathrm{m}$ in diameter in rats and $450 \mu \mathrm{m}$ in humans. ${ }^{7}$ If we had used a smaller probe tip (1-2 $\mathrm{mm})$ and measured sites that were less than $3 \mathrm{~mm}$ apart, we might have been able to identify these very small loci of relative decreased impedance.

\section{Skin condition at selected sites}

Hyvarinen and Karlsson ${ }^{8}$ used a concentric probe with a central electrode surrounded by a ring that allowed com- 
Table 8. TE 1 Hypothesis Test Results ( $P$ Values)

\begin{tabular}{lccc}
\hline Test & $N\left(\right.$ Prognos $\left.^{\mathrm{a}}\right)$ & Prognos $^{\mathrm{a}}$ & PT Probe $^{\mathrm{b}}$ \\
\hline $\mathrm{AP}<\mathrm{MP}$ & 18 & 0.9519 & 0.9423 \\
$\mathrm{AP}<\mathrm{NP}$ & 18 & 0.1189 & 0.1316 \\
$\mathrm{MP}<\mathrm{NP}$ & 19 & 0.0481 & 0.0577 \\
\hline
\end{tabular}

${ }^{\mathrm{a}}$ MedPrevent GmbH, Waldershof, Germany.

${ }^{b}$ Designed for this study.

$\mathrm{AP}$, acupuncture point; MP, on the meridian; NP, off the meridian.

parison of impedance at points $2.5 \mathrm{~mm}$ from the center. They systematically recorded measurements over the entire hand and ear, moving in 1-mm steps, and found distinctive lowresistance points that coincided with classical APs on the ear and on the dorsum of the hand, but no distinctive points on the palmar surface of the hand except at the interphalangeal joints. In retrospect, our choices of PC 8 and its associated NP and MP (on the palm) were not the best for defining a clear-cut difference between AP and non-AP sites because even imperceptible palmar sweating may equalize skin impedance over the entire palm.

APs on the legs, arms, and back were not chosen because preliminary work indicated that the Prognos was unreliable for measuring those sites. Ear APs were not chosen because our probe tips were too large, and when Margolin et al. ${ }^{31}$ assessed the reliability of ESR at ear APs for use in clini- cal trials, they found that active zones in the ear had overall lower impedance, but the measurements at specific points could not be obtained with sufficient accuracy.

\section{Possible inaccurate AP and non-AP point location}

Three experienced acupuncturists, using their knowledge of classical acupuncture charts, anatomical landmarks, palpatory skills, and other sensory cues, came to consensus on locations for the APs and non-APs. All acknowledged that it was more difficult finding a "non-AP" site, which is not part of their usual clinical practice. Despite this difficulty, no sites were chosen without full consensus of the group, so it is unlikely that the points were chosen in error.

\section{Inadequacy of measuring devices for points tested}

The Prognos device was shown to be reliable for measuring the Ting (Jing well) points, located over bone, at the finger and toenail beds. This device, however, had not been tested for reliability in measuring either sites more proximally located on the finger or sites on the forehead or on the palmar surface of the hand. We found that more fleshy areas were not firm enough to deflect the Prognos' probe tip before the outer shell came into contact with the skin, thus increasing the measurement pressure, which might contribute to erroneous measurements.

We found that the impedance of the skin increased significantly with repeated measurements with both the Prog-

Table 9. Prognos $^{\text {a }}$ Median Impedances (k $\Omega$ )

\begin{tabular}{|c|c|c|c|c|c|c|c|c|c|}
\hline \multirow[b]{2}{*}{ Subject } & \multicolumn{3}{|c|}{$G B 14$} & \multicolumn{3}{|c|}{$P C 8$} & \multicolumn{3}{|c|}{$T E 1$} \\
\hline & $A P$ & $M P$ & $N P$ & $A P$ & $M P$ & $N P$ & $A P$ & $M P$ & $N P$ \\
\hline 1 & 19 & 1323 & 8072 & 3171 & 2928 & 3242 & 3032 & 33,739 & 4847 \\
\hline 2 & 4657 & 175 & 706 & 3133 & 15,658 & 2701 & 6882 & NA & 60,739 \\
\hline 3 & 620 & 129 & 2046 & 2568 & 2331 & 2882 & 4604 & 2000 & 1607 \\
\hline 4 & 258 & 3408 & 669 & 860 & 569 & 1247 & 4378 & 733 & 451 \\
\hline 5 & 2521 & 7072 & 1161 & 2843 & 2569 & 2909 & 1419 & 2376 & 2762 \\
\hline 6 & 1471 & 973 & 269 & 5522 & 3751 & 5446 & 33,301 & 18,632 & 10,125 \\
\hline 7 & 731 & 1167 & 503 & 3341 & 4081 & 9491 & 26,312 & 11,905 & 20,180 \\
\hline 8 & 10,339 & 740 & 7013 & 7555 & 7369 & 3612 & 1808 & 9859 & 4038 \\
\hline 9 & 57 & 151 & 827 & 5485 & 1035 & 1349 & 2552 & 4797 & 810 \\
\hline 10 & 868 & 299 & 588 & 2674 & 2112 & 5315 & 9290 & 1720 & 17,392 \\
\hline 11 & 46 & 57 & 107 & 1817 & 3294 & 3735 & 1491 & 1405 & 3281 \\
\hline 12 & 5332 & 56 & 374 & NA & NA & NA & 15,789 & 4120 & 15,302 \\
\hline 13 & 62 & 151 & 151 & 39,957 & 27,620 & 30,762 & 18,038 & 39,641 & 41,604 \\
\hline 14 & 33,964 & 450 & 9329 & NA & 34,608 & 40,961 & NA & 37,371 & 59,136 \\
\hline 15 & 658 & 252 & 1734 & 1025 & 1828 & 1841 & 22,300 & 2218 & 47,440 \\
\hline 16 & 803 & 367 & 21,628 & 3879 & 3872 & 6849 & 12,395 & 3553 & 14,213 \\
\hline 17 & 105 & 1065 & 5390 & 5309 & 1479 & 1400 & 2283 & 387 & 1006 \\
\hline 18 & 1185 & 387 & 3332 & 4107 & 2204 & 1393 & 11,826 & 2446 & NA \\
\hline 19 & 75 & 165 & 1669 & 1871 & 3756 & 1521 & 21,822 & 4037 & 31,361 \\
\hline 20 & 27 & 142 & 237 & 3704 & 2066 & 1143 & 2854 & 1014 & 12,493 \\
\hline
\end{tabular}

${ }^{\mathrm{a} M e d P r e v e n t} \mathrm{GmbH}$, Waldershof, Germany.

GB, Gallbladder; PC, Pericardium; TE, Triple Energizer; AP, acupuncture point; MP, on the meridian; NP, off the meridian. 
Table 10. PT Probe ${ }^{\mathrm{a}}$ Median Impedances (K $\Omega$ )

\begin{tabular}{|c|c|c|c|c|c|c|c|c|c|}
\hline \multirow[b]{2}{*}{ Subject } & \multicolumn{3}{|c|}{$G B \quad 14$} & \multicolumn{3}{|c|}{$P C 8$} & \multicolumn{3}{|c|}{ TE 1} \\
\hline & $A P$ & $M P$ & $N P$ & $A P$ & $M P$ & $N P$ & $A P$ & $M P$ & $N P$ \\
\hline 1 & 93 & 139 & 239 & 2862 & 2432 & 1167 & 2193 & 5179 & 2039 \\
\hline 2 & 574 & 167 & 243 & 5911 & 10,909 & 4613 & 3506 & 67,868 & 10,153 \\
\hline 3 & 237 & 327 & 598 & 1869 & 1190 & 2440 & 6746 & 1564 & 1131 \\
\hline 4 & 796 & 2000 & 473 & 2020 & 1254 & 3094 & 5508 & 1936 & 2419 \\
\hline 5 & 604 & 5446 & 685 & 2477 & 2029 & 2591 & 3486 & 2938 & 3220 \\
\hline 6 & 786 & 284 & 324 & 10,019 & 2487 & 3387 & 66,283 & 24,289 & 18,697 \\
\hline 7 & 133 & 597 & 596 & 1932 & 2430 & 3390 & 7308 & 6092 & 3949 \\
\hline 8 & 716 & 238 & 1662 & 2158 & 1607 & 1261 & 6065 & 41,423 & 3172 \\
\hline 9 & 98 & 163 & 217 & 1927 & 866 & 524 & 553 & 1638 & 796 \\
\hline 10 & 736 & 205 & 234 & 2104 & 1951 & 1977 & 1051 & 1391 & 2306 \\
\hline 11 & 107 & 115 & 113 & 1309 & 2760 & 2037 & 1059 & 895 & 1635 \\
\hline 12 & 730 & 111 & 183 & 66,607 & 50,282 & 11,669 & 14,606 & 15,225 & 39,007 \\
\hline 13 & 131 & 157 & 138 & 3547 & 3415 & 3023 & 921 & 762 & 5305 \\
\hline 14 & 3574 & 130 & 984 & 18,357 & 18,237 & 17,308 & 19,196 & 4746 & 6939 \\
\hline 15 & 591 & 249 & 625 & 969 & 1511 & 1638 & 3100 & 2556 & 4010 \\
\hline 16 & 3813 & 587 & 8273 & 2087 & 2581 & 2850 & 2923 & 2466 & 4619 \\
\hline 17 & 128 & 655 & 1068 & 1585 & 1322 & 1687 & 1422 & 909 & 2142 \\
\hline 18 & 123 & 334 & 764 & 2794 & 1322 & 948 & 6957 & 1862 & 15,275 \\
\hline 19 & 134 & 477 & 718 & 2126 & 4084 & 1970 & 6588 & 2464 & 7967 \\
\hline 20 & 111 & 120 & 159 & 2673 & 2205 & 1430 & 2176 & 1422 & 4911 \\
\hline
\end{tabular}

aDesigned for this study.

GB, Gallbladder; PC, Pericardium; TE, Triple Energizer; AP, acupuncture point; MP, on the meridian; NP, off the meridian.

nos and the PT probe devices. This agrees with Noordergraaf and Silage, ${ }^{15}$ who found that the impedance increases to a plateau dependent on probe size, inclination, skin dryness, and proximity of underlying bone structure. Another possible explanation is that, after cleansing the probe tips with ethyl alcohol at the beginning of each session, the probe tips acquired a layer of debris with subsequent measurements that increased the impedance. Because all of these factors were approximately constant for each location we tested, and the measurement order was randomized, this had no effect on our statistical analysis.

\section{CONCLUSIONS}

Within the reliability limits of our instrumentation and the research design, none of the APs tested had statistically lower skin impedance than nearby control points. These results are not consistent with earlier studies that detected lower skin impedance at APs. Further study is warranted to determine whether MPs have lower skin impedance than nearby NPs. Our study suggests that caution is warranted when developing, using, and interpreting results from electrodermal screening devices. Further studies are needed to clarify the clinically important and controversial hypothesis that APs are sites of lower impedance.

\section{REFERENCES}

1. Niboyet JEH. Part 2: Lower electrical resistance on skin surface corresponding to cutaneous acupuncture points and meridians [in French]. In: Nibeyet JEH, Bourdiol RJ, Regard PG, eds. Treatise on Acupuncture. Paris: Maisonneuve, 1963:326-333.

2. Nakatani Y. On the nature of the acupuncture points and meridians. J Jpn Orient Med 1953;3:39-49.

3. Voll R. Twenty years of electroacupuncture diagnosis in Germany: A progress report. Am J Acupuncture 1975;3:7-17.

4. Reichmanis M, Marino AA, Becker RO. Laplace plane analysis of impedance between acupuncture points H-3 and H-4. Comp Med East West 1977;5(3-4):289-295.

5. Reichmanis M, Becker RO. Physiological effects of stimulation at acupuncture loci: A review. Comp Med East West 1978;6:67-73.

6. Kwok G, Cohen M, Cosic I. Mapping acupuncture points using multi channel device. Australas Phys Eng Sci Med 1998; 21:68-72.

7. Jakoubek B, Rohlicek V, Changes of electrodermal properties in the "acupuncture points" on men and rats. Physiol Bohemoslov 1982;31:143-149.

8. Hyvarinen J, Karlsson M. Low-resistance skin points that may coincide with acupuncture loci. Med Biol 1977;55:88-94.

9. Halek J, Opavsky J, Kolarova J. Problems of the skin resistance measuring in randomly chosen and so-called active points of the skin. Acta Univ Palacki Olomuc Fac Med 1984; 107:51-62.

10. Cho SH, Chun SI. The basal electrical skin resistance of acupuncture points in normal subjects. Yonsei Med J 1994;35: 464-474. 
11. Chiou SY, Chao CK, Yang YW. Topography of low skin resistance points (LSRP) in rats. Am J Chin Med 1998;26:19-27.

12. Brown ML, Ulett GA, Stern JA. Acupuncture loci: Techniques for location. Am J Chin Med 1974;2:67-74.

13. McCarroll GD, Rowley BA. An investigation of the existence of electrically located acupuncture points. IEEE Trans Biomed Eng 1979;26:177-181.

14. Martinsen OG, Grimnes S, Morkrid L, Hareide M. Line patterns in the mosaic electrical properties of human skin: A cross-correlation study. IEEE Trans Biomed Eng 2001;48: 731-734.

15. Noordergraaf A, Silage D. Electroacupuncture. IEEE Trans Biomed Eng 1973;20:364-366.

16. Johng HM, Cho JH, Shin HS. Frequency dependence of impedances at the acupuncture point Quze (PC3). IEEE Eng Med Biol Mag 2002;21:33-36.

17. Barlea NM, Sibianu H, Ciupa RV. Electrical detection of acupuncture points. Acta Electrotech Napocensos 2000;14: 59-61.

18. Becker RO, Reichmanis M, Marino AA, Spadara JA. Electrophysiological correlates of acupuncture points and meridians. Psychoenergetic Systems 1976;1:105-112.

19. Ahn AC, Wu J, Badger GJ, et al. Electrical impedance along connective tissue planes associated with acupuncture meridians. BMC Complement Altern Med 2005;5:10.

20. Ghaznavi C, Chrucky R. Localization of acupuncture loci by electrical impedance measurements and their relations to blood flow. Presented at: 2nd Annual New England Bioengineering Conference. Worcester Polytechnic Institute, Worcester, MA, 1974.

21. Rosendal T. Studies on the conductivity properties of human skin to direct current. Acta Physiol Scand 1943;5:130-151.

22. Colbert AP, Hammerschlag R, Aickin M, McNames J. Reliability of the Prognos electrodermal device for measurements of electrical skin resistance at acupuncture points. J Altern Complement Med 2004;10:610-616.
23. Treugut H, Görner C, Lüdtke R, Burghardt V. Reliability of energetic meridian measurement with Prognos ACR [in German]. Forsch Komplementärmed 1998;5:284-289.

24. Tsunami D, McNames J, Colbert A, et al. Variable frequency bioimpedance instrumentation. Presented at: Annual International Conference of the IEEE Engineering in Medicine and Biology, San Francisco, CA, September 1-5, 2004, IEEE EMBS-Proceedings 2004:2386-2389.

25. Shrout PE, Fleiss JL. Intraclass correlations: Uses in assessing rater reliability. Psychol Bull 1979;86:420-428.

26. McGraw KO, Wong SP. Forming inferences about some intraclass correlation coefficients. Psychol Methods 1996;1: 30-46. [corrections in no. 4:390.]

27. Cox DR, Stuart A. Some quick sign tests for trend in location and dispersion. Biometrika 1955;42:80-85.

28. Reichmanis M, Marino AA, Becker RO. Electrical correlates of acupuncture points. IEEE Trans Biomed Eng 1975;22:533-535.

29. Reichmanis M, Marino AA, Becker RO. D.C. skin conductance variation at acupuncture loci. Am J Chin Med 1976;4:69-72.

30. Reichmanis M, Marino AA, Becker RO. Laplace plane analysis of transient impedance between acupuncture points Li-4 and Li-12. IEEE Trans Biomed Eng 1977;24:402-405.

31. Margolin A, Avants SK, Birch S, et al. Methodological investigations for a multisite trial of auricular acupuncture for cocaine addiction: A study of active and control auricular zones. J Subst Abuse Treat 1996;13:471-481.

Address reprint requests to: Agatha P. Colbert, M.D. Helfgott Research Institute National College of Natural Medicine 049 SW Porter Street Portland, OR 97201

E-mail: acolbert@ncnm.edu 
Copyright of Journal of Alternative \& Complementary Medicine is the property of Mary Ann Liebert. Inc. and its content may not be copied or emailed to multiple sites or posted to a listserv without the copyright holder's express written permission. However, users may print, download, or email articles for individual use. 